
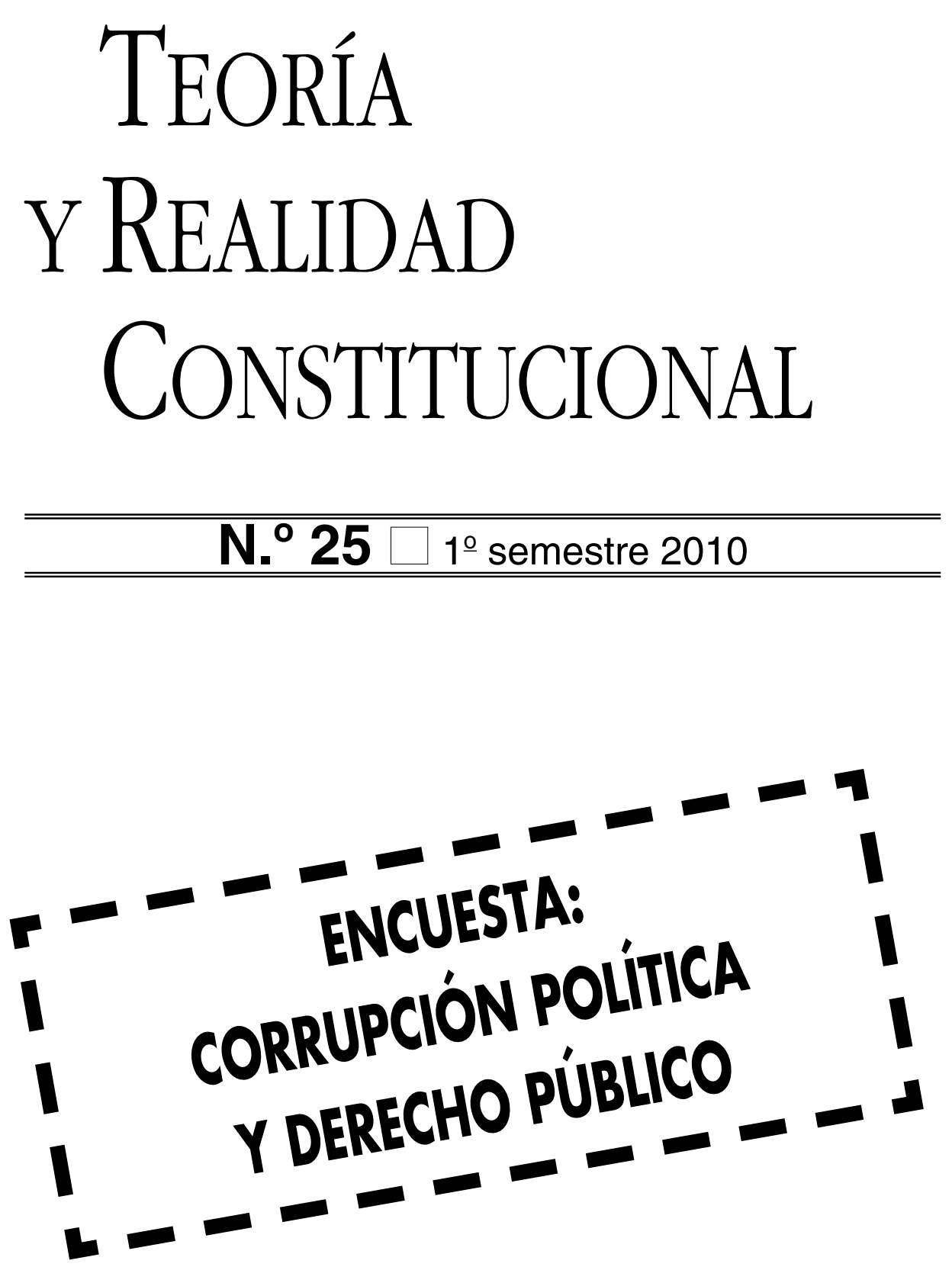


\title{
EL CONVENIO EUROPEO DE DERECHOS HUMANOS ¿UNA DECLARACIÓN ESCRITA DE DERECHOS AL ESTILO CONTINENTAL PARA EL REINO UNIDO? ${ }^{1}$
}

\author{
SUSANA SÁNCHEZ FERRO \\ Profesora Contratada Doctora de Derecho Constitucional \\ Universidad Autónoma de Madrid
}

\author{
SUMARIO \\ I. Introducción. \\ II. El camino hacia la aprobación de la Hu- \\ man Rights Act. \\ III. Los rasgos definitorios de la Human \\ Rights Act: ¿una declaración de dere- \\ chos? \\ IV. Conclusión.
}

\section{INTRODUCCIÓN}

El 31 de diciembre de 1999 toda Europa se mantenía en vilo ante el temor de una posible catástrofe financiera mundial producida por la adaptación de las monedas vernáculas a la moneda común europea, el euro. Toda Europa, no, como decía un afamado cómic de todos conocido; en una isla de nuestro viejo continente, tradicionalmente marcada por su resistencia a la incorporación en su sistema jurídico de elementos foráneos, una parte importante de la élite política seguramente no podía conciliar el sueño, pero por una causa bien distinta: la inminente llegada del año que marcaría la entrada en vigor en el Reino Unido de la Human Rights Act, una norma que, venciendo siglos de resistencia, incorporaba el Convenio Europeo de Derechos Humanos como Derecho propio de aquel lugar, «extraño" lugar.

1 El presente trabajo se corresponde con la comunicación presentada al VIII Congreso de la Asociación de Constitucionalistas de España que se desarrolló el 4 y 5 de marzo en San Sebastián. 
Mientras que la adaptación al euro de los Estados miembros de la Unión Europea había sido anunciada a bombo y platillo por todos los rincones del Continente y los ecos de lo que podría suceder se habían extendido allende los mares, una de las revoluciones más importantes de nuestro siglo se producía de forma silenciosa y sin levantar sospechas, siquiera de buena parte de los habitantes del territorio en el que estaba teniendo lugar, y que hasta ese momento había resistido más o menos bien (recordemos esa primera intrusión que supuso en el Derecho británico la entrada en vigor de los Tratados de las Comunidades Europeas) los vientos jurídicos provenientes del viejo Continente ${ }^{2}$.

Pero ¿cómo y por qué en aquél lugar del mundo en dónde se preciaban de ser unos de los máximos adalides de la libertad y en dónde se presumía de ello, hubo de producirse este sorprendente hecho? Y, sobre todo, ¿cómo pudo producirse el cambio si, aparentemente, ningún tsunami amenazaba con destruir los cimientos de un sistema que llevaba funcionando siglos y donde ninguna multitud se había echado a las calles pidiendo amenazante un cambio en el sistema?

\section{EL CAMINO HACIA LA APROBACIÓN DE LA HUMAN RIGHTS ACT}

\section{II.1. Situación PREvia a la Aprobación de la Human Rights ACT}

El Reino Unido, se nos dice, nunca ha sido ajeno a la cultura de derechos existente en el Continente europeo, pues colaboró intensamente en la elaboración del Convenio Europeo de Derechos Humanos. Además, en el proceso de descolonización, el Reino Unido, pieza clave, ofreció apoyo al proceso de elaboración de declaraciones de derechos escritas, como la adoptada en Canadá. Por ello se pensaba que ningún Estado podía dar lecciones de libertad al Reino Unido, país en el que la protección de la libertad era tal que no se necesitaba importar un sistema de protección de derechos foráneo 3 .

El prestigioso Anthony Lester describe la situación en los años 50 del siglo pasado en el Reino Unido como una época gloriosa, en la que reinaba en el país la satisfacción por poseer una estructura constitucional ejemplar, flexible y adaptable, con un Gobierno democrático que desempeñaba sus funciones con el consentimiento de los gobernados en un marco de libertad y bajo el imperio de la ley. La sociedad se incardinaba en el espacio multirracial de la Commonwealth, y el país era líder en los esfuerzos que se estaban realizando en el marco de Naciones Unidas y el Consejo de Europa para consolidar la paz en el Continente.

2 KLUG, F.: Values for a Godless Age. The Story of the UK's New Bill of Rights, Penguin Books, England, 2000, pág. 29.

3 Idem, pág. 5. 
En este contexto, el sistema constitucional británico se veía como preferible, incluso superior, a las constituciones escritas de Norteamérica y de la Europa occidental, pues poseía las garantías que le proporcionaba el sistema parlamentario de gobierno, unitario y centralizado, con Gobiernos de Gabinete fuertes, a los que auxiliaba un cuerpo de servidores públicos independientes y reclutados con base en el sistema del mérito. Los derechos, que en Europa continental y Norteamérica se consideraban, con cierta retórica desde el punto de vista británico, inalienables o fundamentales, se verían sin duda mejor protegidos a través de la vigilancia de los parlamentarios y de las leyes aprobadas por el Parlamento; gracias también a la integridad de los funcionarios - producto de su cuidada formación y designación-, y a través de una prensa libre floreciente en el país, y un poder judicial independiente, integrado por abogados incorporados al mismo tras una exitosa carrera como tales.

El concepto de igualdad ante la Ley de Dicey serviría mejor a la administración de justicia, a la consecución de un gobierno eficaz, y a la justicia individual, que la separación artificial entre Derecho público y Derecho privado de los sistemas de civil law, con sus remedios propios de Derecho Administrativo. En el Reino Unido, la Constitución flexible, sin separación rígida de poderes, y la revisión de la actividad ordinaria de la Administración por los tribunales de justicia sería garantía suficiente para una sociedad deseosa de vivir en libertad ${ }^{4}$.

Todavía hoy puede oírse en el Reino Unido la misma retórica: «Este es un país que nunca necesitó de revoluciones para adaptarse y cambiar. Aparte de una guerra civil y de decapitar a un par de monarcas y un par de batallas entre las naciones que habitan estas islas, los cambios aquí se han producido fundamentalmente por medios pacíficos. En respuesta a diferentes olas de protesta popular (...) las élites aprendieron a aceptar la corriente de la historia y a compartir el poder hasta la llegada de la democracia. Los recientes movimientos para "devolver" el poder a Escocia, Gales e Irlanda del Norte (devolution) y para reformar la House of Lords son ejemplos de esta capacidad para el cambio evolutivo. No necesitamos majestuosos documentos como las constituciones para ser uno de los países del mundo con mayor grado de libertad. Tampoco importa que seamos una de las pocas democracias del mundo que no poseemos alguna forma de declaración de derechos" ${ }^{5}$.

En este marco hay que interpretar la adhesión del Reino Unido al Convenio Europeo de Derechos Humanos en el año $1951^{6}$. El Convenio Europeo de Derechos Humanos obligó desde entonces al Reino Unido internacional-

4 LESTER, A.: "The Constitution: Decline and Renewal", The Changing Constitution, ed. Jeffrey Jowell and Dan Oliver ( $2^{\mathrm{A}}$ ed.), Clarendon Press, Oxford, 1989, págs. 345 y 436.

5 KLUG, F.: Values for a Godless Age. The Story of the UK's New Bill of Rights, cit., pág. 29 [la traducción es nuestra].

6 Idem, pág. 20 y BRADLEY, A.W.: "The sovereignty of Parliament- in Perpetuity?", The Changing Constitution, cit., pág. 44. El Reino Unido ratificó el Convenio en el año 1951 y el Convenio entró en vigor dos años más tarde. 
mente, pero no constituyó Derecho interno del país ${ }^{7}$. Antes de la aprobación de la Human Rights Act, los jueces y tribunales no eran competentes para basar en el Convenio sus decisiones, como parámetro de las mismas, salvo que el Parlamento hubiera decidido incorporar algún aspecto del mismo a alguna ley concreta; sólo en ese punto los tribunales podían tomar dicho Derecho como parámetro de su decisión, eso sí, manteniéndose fieles, no al sistema de derechos del propio Convenio, sino a la decisión del Parlamento de incorporar dicho elemento al Derecho interno. El cumplimiento del Convenio quedaba, pues, a la voluntad del Parlamento soberano por mor del principio "diceyniano" de soberanía parlamentaria. Este principio, dicho sea de paso, sigue aún hoy vigente y sobre él sigue pivotando todo el sistema británico, incluso tras la aprobación de la Human Rights Act.

Señala Bradley que los jueces durante este tiempo habían declarado que podían hacer uso del Convenio para favorecer una interpretación de las leyes en coherencia con el mismo. Lord Scarman se manifestaba incluso partidario de que los jueces tuvieran en cuenta el Convenio cuando estuvieran considerando una cuestión de Derecho no decidida previamente (an undecided question of law). Pero muchos jueces se mostraban reticentes a dar efectividad al Convenio por esta vía, decantándose por el seguimiento de los parámetros tradicionales de interpretación estatutaria clásicos; la efectividad del Convenio en todo caso estaba lejos de alcanzar aquélla que le correspondería de convertirse en Derecho interno ${ }^{8}$.

Llama la atención, por ejemplo, que sólo desde el año 1966 los sucesivos Gobiernos británicos permitieron a aquéllos que sufrieran una violación de alguno de los derechos reconocidos en el Convenio Europeo de Derechos Humanos en territorio británico, ya fueran o no ciudadanos del país, acudir a Estrasburgo y reclamar contra el Reino Unido en las instancias competentes?. Se hablaba del largo camino que uno tenía que recorrer para llegar a Estrasburgo (pues los jueces británicos no podían tomar en consideración cuestiones sustantivas relativas a los derechos fundamentales del Convenio en conflicto en el caso concreto $)^{10}$. De hecho, hasta hace poco, no era apropiado hablar

7 BRADLEY, A.W.: "The sovereignty of Parliament- in Perpetuity?», en The Changing Constitution, cit., pág. 45.

8 Idem, pág. 46.

9 BRADLEY. A.W.: "The sovereignty of Parliament- in Perpetuity?", en The Changing Constitution, cit., pág. 45. KLUG, F.: Values for a Godless Age. The Story of the UK's New Bill of Rights, cit., pág. 20.

10 KENNEDY, H.: Foreword to Klug, Francesca: Values for a Godless Age. The Story of the UK's New Bill of Rights, Penguin Books, England, 2000, pág. xi. Un ejemplo de lo que señala Helena Kennedy es el caso Malone, que luego llegaría al TEDH, en dónde se pretendió que los jueces británicos reconociesen la existencia de un derecho al secreto de las comunicaciones frente a la intervención de las mismas por la policía británica (dentro del llamado right to privacy del artículo 8 del CEDH) y el juez señaló que el Convenio no podía ser utilizado como base para crear un derecho no reconocido en el Derecho inglés [Malone v. Metropolitan Police Commissioner [1979] Ch. 344] citado por BRADLEY, A.W.: "The sovereignty of Parliament- in Perpetuity?", en The Changing Constitution, cit., pág. 45. 
de derechos fundamentales, y menos escritos en el Reino Unido, sino de civil liberties (libertades no escritas frente a derechos fundamentales escritos) ${ }^{11}$. Además, la misma idea de los derechos fundamentales se concebía como el camino hacia el individualismo extremo y hacia el final de la cohesión social ${ }^{12}$.

El punto de partida de la teoría de las civil liberties es que todo ciudadano puede hacer lo que desee siempre que no esté prohibido por el common law o por la ley (statute) [AG v. Guardian Newspapers (No 2) [1990], IAC 109]. El sistema de common law protegería mejor estas "libertades civiles" que las declaraciones de derechos, según Dicey, porque proveería de remedios efectivos frente a la vulneración de las mismas. El Gobierno, además, tendría más difícil suspender los derechos no escritos producto de la jurisprudencia de los tribunales ${ }^{13}$. Por supuesto, a esto habría que sumar una garantía adicional, y es el hecho de que el concepto de soberanía parlamentaria vigente en el sistema habría de acompañarse del inseparable principio, también fundamental, del imperio de la ley o Rule of Law, según el cual el Parlamento no podría (moralmente) usar su poder legislativo para derogar las libertades derivadas del common law y nunca derogaría normas tales como la Bill of Rights de 1688 o el Habeas Corpus Act, salvo en situaciones de emergencia ${ }^{14}$.

El sistema de libertades británico es, o incluso es posible que debamos decir, era, un sistema basado en remedios, más que en derechos. Este sistema reconoce a los individuos ciertos intereses fundamentales. Cuando estos intereses coinciden con los intereses internacionalmente reconocidos puede decirse que el common law ofrece más o menos la misma protección que los derechos fundamentales.

El common law protege especialmente los derechos a un juicio justo con todas las garantías, a la libertad personal, a la reputación y los derechos de propiedad, y, en ocasiones, lo hace mejor que muchas declaraciones de derechos. No debemos olvidar que muchos de estos derechos tienen su origen en la cultura legal de las islas británicas. En cualquier caso, otros derechos internacionalmente garantizados por el Convenio Europeo de Derechos Humanos carecen de protección o tienen una protección muy débil en el sistema de common law británico. Es el caso del right to privacy, que engloba varios de los derechos que recoge el artículo 8 del Convenio Europeo de Derechos Humanos y nuestro artículo 18 de la CE. En este campo existen remedios parciales, como la acción de allanamiento (trespass), de difamación, o de ruptu-

11 KLUG, F.: Values for a Godless Age. The Story of the UK's New Bill of Rights, cit., pág. 5.

12 Klug explica cómo esta visión era habitual en época de Margaret Thatcher y cómo dicha concepción todavía pesa en la política británica; de ahí la insistencia de aquéllos que sí han adoptado la retórica de los derechos fundamentales de mencionar, cada vez que hablan de los derechos, que éstos son sólo una cara de la moneda, y que la otra son las responsabilidades. KLUG, F.: Values for a Godless Age. The Story of the UK's New Bill of Rights, cit., págs. 13, 50 y 51.

13 KLUG, F.: Values for a Godless Age. The Story of the UK's New Bill of Rights, cit., pág. 34, quien sitúa la base de la teoría en el famoso jurista A.V. Dicey y su Law of the Constitution.

14 Idem, pág. 35 y BRADLEY. A.W.: "The sovereignty of Parliament- in Perpetuity?", en The Changing Constitution, cit., pág. 43. 
ra de la confianza (que no cubren toda intromisión en el derecho a la intimidad personal, familiar o a la propia imagen ${ }^{15}$. También nos encontramos con esta carencia en relación con el derecho a la no discriminación; el Parlamento británico remedió parcialmente esta laguna a través de la publicación de una serie de Leyes sobre discriminación por razón de raza o sexo ${ }^{16}$.

\section{II.2. El CAMBIO EN EL STATUS QUO}

¿Por qué se produce un cambio en el status quo y un cierto viraje hacia una cultura de derechos al estilo continental?

En primer lugar, en algunos sectores de la intelectualidad británica existía la percepción de que el Reino Unido se estaba quedando aislado del resto del Continente ante la falta de una Constitución escrita, de una declaración de derechos y de un sistema de Derecho público coherente. Este estado de cosas debía ser remediado ${ }^{17}$.

Si del sistema constitucional británico cabría resaltar algo, esto era precisamente su flexibilidad y su capacidad de cambio como elementos positivos, pero también en este punto habría fallado el sistema al no haberse adaptado el país y su sistema jurídico a los cambios que necesitaba. En este sentido, manifestaba algún autor, es peligroso tener siempre que confiar en remedios foráneos para resolver los defectos del propio sistema ${ }^{18}$.

No eran pocos los que pensaban que el sistema de garantías de las libertades en el Reino Unido no funcionaba tan bien como se decía. Los límites

15 KLUG, F.: Values for a Godless Age. The Story of the UK's New Bill of Rights, cit. págs. 31 y 36. Francesca Klug nos dice que muchos ciudadanos británicos desconocen absolutamente que esta sea la situación en el Derecho inglés y pone el ejemplo de la señora McLeod, quien descubrió, para su sorpresa, que a pesar de que su marido, separado de ella, sus hijos, el abogado del primero y la policía entraron en su casa sin su permiso para recoger algunos muebles, como parte del acuerdo de separación, tres días antes de que la señora McLeod debiera legalmente entregar la propiedad, la acción de allanamiento (trespass) en el ordenamiento inglés sólo le permitía actuar en los tribunales contra los primeros, pero no contra la policía, pues el Derecho inglés no contenía un derecho a la intimidad en sentido amplio (right to privacy) que le protegiera y sólo le ofrecía remedios frente a los demás implicados. Finalmente la señora McLeod tuvo que esperar nueve años para que el TEDH le diera la razón y declarase vulnerado su derecho a la vida privada y familiar del artículo 8 del Convenio [McLeod v. UK (1998), 27 EHRR 493, citado por Klug]. Es un sistema, el inglés, de acciones y remedios.

16 Idem, pág. 37. Señala Klug que está muy bien que el Parlamento incremente los derechos protegidos por una declaración de derechos, pero que por lo limitado del lenguaje que usan las leyes y porque se adaptan peor a los nuevos desarrollos de aquéllos, nunca pueden sustituir a una declaración de derechos.

17 LESTER, A.: "The Constitution: Decline and Renewal", The Changing Constitution, cit., págs. 345 y 368. Así se deduce también del libro de KLUG, Values for a Godless Age. The Story of the UK's New Bill of Rights, cit., o, por ejemplo, de sus comentarios en la página 7. Vid. también, BOGDANOR, V.: The New British Constitution, Hart Publishing, Oxford and Portland, Oregon, 2009, pág. 57.

18 LESTER, A.: "The Constitution: Decline and Renewal", The Changing Constitution, cit., págs. 345,368 y 369. 
a la soberanía parlamentaria estaban siendo demasiado débiles en una sociedad en la que la presencia de lo público era cada vez mayor; las minorías se veían necesitadas de una mayor protección frente a la mayoría parlamentaria ${ }^{19}$ y nunca habría habido una igualdad ante la ley, más allá de la formal, entre los gobernantes y los gobernados. Mientras los gobernantes seguían reclamando y consiguiendo en muchos casos inmunidad frente a la ley ordinaria y trataban de evitar verse constreñidos por el Convenio Europeo de Derechos Humanos, los ciudadanos se encontraban cada vez con mayores obstáculos para enfrentarse a los poderes públicos ${ }^{20}$.

Los hitos en el camino

Fue el Gobierno de Tony Blair el que decidió incorporar, mediante la aprobación de la Human Rights Act, el Convenio Europeo de Derechos Humanos como Derecho interno tras su victoria en las elecciones de 1997. No deja de sorprender que el Gobierno decidiera dar este paso cuando no existían presiones externas a tal fin: su introducción no se produce a raíz de unas elecciones, una revolución, presiones en la calle o alguna directiva europea en tal sentido, tampoco había encuestas al respecto ni lobbies ni presiones de la prensa en tal dirección ${ }^{21}$. Por lo demás, el Gobierno se debate entre los momentos de silencio respecto de la introducción de la norma y los de entusiasmo y publicidad al respecto ${ }^{22}$. Y todo a pesar de encontrarnos ante una norma que ha sido calificada como una de las piezas constitucionales más importantes en la historia del Reino Unido ${ }^{23}$.

Tony Blair presentó su propuesta de incorporar el Convenio Europeo de Derechos Humanos como Derecho interno estando en la oposición. Se trataba de contrarrestar el record negativo de sentencias que el Reino Unido iba acumulando en Estrasburgo y evitar que los ciudadanos británicos tuvieran

19 BRADLEY, A.W.: "The sovereignty of Parliament- in Perpetuity?", en The Changing Constitution, cit., pág. 44; KLUG, F.: Values for a Godless Age. The Story of the UK's New Bill of Rights, cit., págs. 37 y 38; LESTER, A.: "The Constitution: Decline and Renewal", The Changing Constitution, cit., págs. 345, 352 y 368. Lester habla del deterioro del habeas corpus, Klug de la desprotección de un inexistente derecho a reunirse y manifestarse...

20 LESTER, A: "The Constitution: Decline and Renewal", The Changing Constitution, cit., 1989, pág. 345.

21 KLUG, F: Values for a Godless Age. The Story of the UK's New Bill of Rights, cit., págs. 19 y 50 .

22 Idem, págs. 24 y 25.

23 JACK STRAW, Home Secretary [Jack Straw Announces Implementation Date for Human Rights Act, Press Release (Home Office, 18 Mayo de 1999)] citado por KLUG, F.: Values for a Godless Age. The Story of the UK's New Bill of Rights, Penguin Books, England, 2000, págs.7 y 63. La propia Francesca Klug califica la entrada en vigor de la Human Rights Act en octubre del año 2000 como un evento extraordinario en la historia británica, pág.19. Vid. también, FENWICK, H., Phillipson, Gavin, and Masterman, Roger: Judicial Reasoning under the UK Human Rights Act, Cambridge University Press, 2007, pág. 1. 
que acudir a instancias internacionales para exigir responsabilidades a su Gobierno por la vulneración de sus derechos. Desde el laborismo se decía que no se trataba de dar a los individuos nuevos derechos, sino de hacer los ya existentes más accesibles a través de la protección de los tribunales del propio país. Por eso, el proyecto laborista se presentó a consulta bajo el título: "Traer los Derechos a casa: Plan laborista para incorporar el Convenio Europeo de Derechos Humanos en el Reino Unido" ${ }^{24}$. Tony Blair resaltaba que la nueva ley lo que hacía era trasladar la palabra a los jueces británicos frente a los europeos ${ }^{25}$.

Posteriormente el Gobierno laborista presentaría la Human Rights Act como una pieza más de su reforma constitucional, pero como no se quería dar una impresión de izquierda blanda con los derechos, imagen que había contribuido a consolidar la derecha conservadora de Margaret Thatcher, se hizo especial hincapié en que no se trataba de reforzar los derechos sin contrapartida, sino que los derechos conllevan también responsabilidades y que se protegerían desde una visión comunitarista, más que individualista de los mismos. Desde esta perspectiva, la nueva declaración de derechos británica no tendría su foco en la protección de los derechos de los individuos frente a la acción del Estado sino en inculcar una cultura de derechos y deberes mutuos que impregnase la sociedad británica ${ }^{26}$.

Finalmente, en la presentación de la futura Human Rights Act al Parlamento británico, en octubre de 1997, Tony Blair aunaría en su discurso varios de los argumentos señalados:

"The Bill marks a major step forward in the achievement of our programme of reform. It will give people in the United Kingdom opportunities to enforce their rights under the European Convention in British courts rather than having to incur the cost and delay of taking a case to the European $\mathrm{Hu}-$ man Rights Commission and Court in Strasbourg. It will enhance the awareness of human rights in our society. And it stands alongside our decision to put the promotion of human rights at the forefront of our foreign policy ${ }^{27}$.

La Human Rights Act fue aprobada el 9 de noviembre de 1998 y entró en vigor el 2 de octubre del año $2000^{28}$.

24 "Bringing rights Home: Labour's Plan to Incorporate the European Convention on Human Rights into United Kigdom Law" (documento elaborado por JACK STRAW y PAUL BOATENG).

25 KLUG, F.: Values for a Godless Age. The Story of the UK's New Bill of Rights, cit., pág. 62.

26 Idem, págs. 63-64.

27 TONY BLAIR: Rights brought bome: the Human Rights Bill, presented to Parliament by the Secretary of State for the Home Department, by command of her majesty, October 1997.

28 FENWICK, H., PHILLIPSON, G., AND MASTERMAN, R.: Judicial Reasoning under the UK Human Rights Act, Cambridge University Press, 2007, pag.1. 


\section{LOS RASGOS DEFINITORIOS DE LA HUMAN RIGHTS ACT: ¿UNA DECLARACIÓN DE DERECHOS?}

\section{EL ÁMBITO DE APLICACIÓN DE LA NORMA}

Desde el año 1951, el Reino Unido está obligado en el plano internacional a respetar el Convenio Europeo de Derechos Humanos. La Human Rights Act persigue, según su propio, y brevísimo preámbulo, extender la protección de los derechos del Convenio al Derecho interno. Ahora bien, es importante conocer con qué alcance se incorpora el Convenio Europeo de Derechos Humanos. Podemos adelantar que la Human Rights Act no es exactamente una declaración de derechos tal y como la concebimos en Europa, aunque haya sido calificada como tal ${ }^{29}$.

La Human Rights Act no contiene un elenco de derechos definidos por la norma y rodeados de garantías específicas. Desde el punto de vista sustantivo, la Human Rights Act se extiende sólo a los derechos del Convenio, ni más ni menos, o, más bien, menos, si nos ceñimos al artículo 1 de la Ley. Dicho artículo define el ámbito de aplicación de la misma, y lo limita a los derechos recogidos en los artículos 2 a 12 y 14 del Convenio Europeo de Derechos Humanos, a los artículos 1 a 3 del primer protocolo, y a los artículos 1 y 2 del sexto protocolo, interpretados conforme a los artículos 16 y 18 del Convenio. El Convenio recoge básicamente derechos de primera generación, por lo que algunos ven con nostalgia que se haya perdido la oportunidad de ampliar la protección a otros derechos de segunda y tercera generación ${ }^{30}$.

Conforme al artículo primero, queda excluido del ámbito de aplicación de la Human Rights Act el artículo 13 del Convenio Europeo de Derechos Humanos. Este artículo, como es sabido, impone a los Estados miembros la obligación de proporcionar al individuo remedio frente a las vulneraciones de sus derechos reconocidos por el Convenio. Paradójicamente, mientras que el Reino Unido está obligado a proporcionar remedio a dicha vulneración desde el punto de vista de sus obligaciones internacionales, no lo está desde el punto de vista de su propio Derecho interno ${ }^{31}$. No hay más remedios frente a vulneraciones de los derechos del Convenio que, en principio, los que existían antes de la entrada en vigor de la Human Rights $A c t^{32}$. En este sentido, como en muchos otros aspectos, la Human Rights Act, a pesar de suponer un

29 KLUG, F.: Values for a Godless Age. The Story of the UK's New Bill of Rights, cit., págs. 7 y 31. LORD STEYN, "Deference: A Tangled Story" [2005] Public Law pág. 346, citado por LEIGH, I.: "Concluding Remarks", en Judicial Reasoning Under the Human Rights Act, ed. by Helen Fenwick, Gavin Phillipson and Roger Masterman, Cambridge University Press, 2007.

30 KLUG, F.: idem.

31 BOGDANOR, V.: The New British Constitution, cit., pág. 60.

32 LADY HALE, en Campbell v. MGN, (57 [2004] 2 WLR 1232; [2004] 2 AC 457) citado por PHILLIPSON, G.: "Clarity postponed: horizontal effect after Campbell, en FENWICK, H., PHILLIPSON G., AND MASTERMAN, R: Judicial Reasoning Under the Human Rights Act, Cambridge University Press, 2007, pág. 157. 
enorme paso hacia adelante en la protección de los derechos de los ciudadanos británicos, ha sido conservadora en sus términos y se ha mantenido en una posición minimalista. En cualquier caso, a la larga es posible que los efectos de la Human Rights Act puedan derivar en la introducción de una futura declaración de derechos propia en el Reino Unido ${ }^{33}$.

Ciertamente, si una determinada vulneración de derechos no tenía remedio aparejado en el ordenamiento interno, no la tendrá por mor de la $H u$ man Rights Act, pero no es menos cierto que la entrada en vigor de la ley ha supuesto un fuerte impulso para los jueces británicos. Estos se han sentido legitimados, por primera vez, porque entienden que así lo ha querido el Parlamento británico al aprobar la ley que comentamos, para recurrir a técnicas de interpretación que antes de la entrada en vigor de la ley se habrían entendido como demasiado creativas e inadecuadas, por tratarse de órganos del Estado no democráticos ${ }^{34}$. El uso de estas nuevas técnicas, más allá de las estrictas reglas de la interpretación literal de la voluntad del Parlamento como órgano soberano, ha permitido a los jueces, en algunos casos, extender el ámbito de aplicación de remedios ya existentes a casos que previamente no se entendían amparados por tales acciones.

Es el caso, por ejemplo, de la utilización del concepto de breach of confidence para, más allá de su significado inicial y literal, cubrir la protección de informaciones cuya publicación no supone realmente una violación de un deber de confianza por parte de la prensa, pero que se encuentran en el ámbito de las informaciones relativas al derecho a la privacy o derecho a la intimidad en sentido amplio, recogido por el Convenio en su artículo 8 y que por eso se protegerían ${ }^{35}$. Tanto es así que algunos autores, incluidos algunos

33 No conviene dejarse engañar por la retórica de algunos políticos, que desde hace tiempo hablan de la necesidad de introducir una declaración de derechos "puramente" británica en este país. En muchos casos, lejos de perseguir una mayor protección de los derechos fundamentales en el Reino Unido, tales declaraciones persiguen retroceder en el camino recorrido y restringir la protección ofrecida, bajo el disfraz de que la nueva realidad no ha hecho más que erosionar las viejas libertades británicas. El Convenio, que siempre se ha considerado un acuerdo de mínimos entre los diversos países signatarios, para algunos políticos británicos parece ser un techo demasiado alto. Vid., por ejemplo, el artículo de The Guardian del 28 de febrero de 2009, sobre las declaraciones del líder del Partido Conservador, David Cameron (y del liberal Nick Clegg) titulado: "Cameron pledges Bill to restore british freedoms" (en www.guardian.co.uk), o el discurso de Cameron en el Centre for Policy Studies de Londres, el 26 de junio de 2006 (recogido por The Guardian bajo el título: "Cameron promises UK Bill of Rights to replace Human Rights Act").

34 Sobre las nuevas formas de argumentación, sirva como ejemplo lo dicho por KAVANAGH, A. en: "Choosing between sections 3 and 4 of the Human Rights Act 1998: judicial reasoning after Gaidhan v. Mendoza", en Helen Fenwick, Gavin Phillipson and Roger Masterman, Judicial Reasoning Under the Human Rights Act, Cambridge University Press, 2007, págs. 114 y ss.

35 LADY HALE en el caso "Campbell" (dicta): "The 1998 Act does not create any new action between private persons. But if there is a relevant cause of action applicable, the court, as a public authority must act compatibly with both parties' Convention rights. In a case such as this, the relevant vehicle will usually be the action of breach of confidence, as Lord Woolf held in A v. B plc., para. 4" [[2004] 2 WLR 1232], [énfasis añadido]; Citado por Gavin Phillipson en: “Clarity postponed: horizontal effect after Campbell, ed. Helen Fenwick, Gavin Phillipson and Roger Mas- 
de los jueces lores, han llegado a hablar de que la breach of confidence se ha transformado, en el Derecho británico, después de la entrada en vigor de la Human Rights Act, en un tort of misuse of private information ${ }^{36}$.

Antes de la entrada en vigor de la Human Rights Act el Derecho inglés sólo protegía al sujeto frente a publicaciones en prensa o en otros medios de comunicación social de datos relativos a su intimidad cuando estos datos hubieran sido obtenidos vulnerando, el sujeto que comunicaba la información, una obligación de confianza hacia el sujeto sobre el que se informaba. Con la entrada en vigor de la Human Rights Act los tribunales ingleses han interpretado que lo importante no es la existencia de la relación de confianza, sino la propia naturaleza de la información, y si ésta entra dentro de la que pertenece a la intimidad del sujeto se presumirá la violación de la confianza. Así, la acción británica de breach of confidence se reinterpreta y se diluye en el ámbito del derecho protegido por el artículo $8 \mathrm{CEDH}$ (caso Campbell) ${ }^{37}$.

\section{LOS POSIBLES EFECTOS HORIZONTALES DE LA NORMA Y EL ALCANCE DE LOS DERECHOS PROTEGIDOS POR LA HUMAN RightS ACT}

Señalábamos que la Human Rights Act no es exactamente una declaración de derechos como las que conocíamos hasta ahora; nos encontramos más bien ante una declaración de derechos por remisión, si cabe decir tal cosa. El artículo 6 (1) de la Human Rights Act señala que las autoridades públicas deben actuar de forma compatible con los derechos del Convenio Europeo de Derechos Humanos enumerados en el artículo primero de la $\mathrm{Hu}$ man Rights Act. La Human Rights Act no define por si misma estos derechos, como hemos visto, sino que remite la definición de los mismos al Convenio. Cualquier actuación incompatible con éstos es ilegal de acuerdo con el artículo 6 (1), aunque con matices, eso sí, derivados del principio de soberanía parlamentaria, que nunca ha desaparecido de escena, aunque haya visto algo relegado su papel.

Se ha discutido profusamente en la doctrina el alcance del término autoridad pública al que hace referencia este artículo 6. Aunque la discusión escapa

terman, Judicial Reasoning Under the Human Rights Act, Cambridge University Press, 2007, págs. 157-158. No todos los jueces opinan igual o son igual de contundentes que Lady Hale, como señala el propio Phillipson en el artículo mencionado (págs. 157-167).

El caso Campbell se refiere a la información dada por determinada revista del corazón de que la modelo había sido drogadicta y estaba sometiéndose a un tratamiento de desintoxicación en Narcóticos anónimos y a las fotos publicadas, tomadas fuera de la clínica, en la que aparecía la modelo junto a otras personas que seguían el tratamiento.

36 FENWICK, H., PHILLIPSON, G. and MASTERMAN, R: Judicial Reasoning Under the Human Rights Act, Cambridge University Press, 2007, pág. 18.

37 Vid. PHILLIP, G.: "The common law, privacy and the Convention" en ed. Helen Fenwick, Gavin Phillipson and Roger Masterman, Judicial Reasoning Under the Human Rights Act, Cambridge University Press, 2007, págs. 215 y ss, y del mismo autor, en la misma obra, "Clarity postponed: horizontal effect after Campbell, págs. 156-158. 
el marco del presente trabajo merece la pena resaltar que, según el apartado 3 de este mismo artículo 6 de la Human Rights Act, el concepto de autoridad pública se refiere a cualquier persona que desempeñe funciones públicas, incluidos los jueces y tribunales ordinarios. En este sentido, este apartado tercero del artículo 6 ha sido el pilar en el que se han apoyado aquellos que, como Lady Hale, han defendido que la Human Rights Act tiene efectos horizontales, aunque no contenga ninguna disposición expresa al respecto ${ }^{38}$. Lord Irvine, el Lord Chancellor, se encuentra entre los que afirman que esta disposición perseguía precisamente este objetivo, ya que la obligación de los jueces de actuar conforme al Convenio les debería llevar a aplicar el common law, de aplicación en muchas relaciones inter privatos, conforme al Convenio (interpretación conforme tal y como se entiende en los sistemas constitucionales europeos).

El reconocimiento por parte de los jueces de los efectos horizontales de la norma es desigual y fragmentario. No todos los jueces, incluidos los jueces lores de la House of Lords, reconocen efectos horizontales a la misma y entre los que los reconocen, no todos lo hacen respecto de cualquier ámbito de las relaciones entre particulares. Los efectos se han ido desarrollando caso por caso, pragmáticamente ${ }^{39}$.

La pregunta que surge en este contexto es la de si la incorporación de los derechos del Convenio ha supuesto la incorporación también de la jurisprudencia del Tribunal Europeo de Derechos Humanos, y con qué alcance. La ley, en el artículo 2, dispone que cuando un juez deba resolver un caso en el que esté implicado un derecho del Convenio, aquél deberá "tomar en consideración" la jurisprudencia del Tribunal Europeo de Derechos Humanos (y de la Comisión) contenida en sus sentencias, así como las decisiones, declaraciones u opiniones de éste (art. 2.1 Human Rights Act). Se ha dicho que esto permitiría a los jueces británicos tomar el Convenio y la jurisprudencia del Tribunal Europeo como un punto de partida más que como un punto de llegada y extender el ámbito de protección de los derechos más allá de lo que lo ha hecho el propio Tribunal Europeo de Derechos Humanos. Ello podría y debería desatar un diálogo con el Tribunal Europeo que sería fructífero para ambos, ya que el Reino Unido pasaría por fin de ser un sujeto pasivo del Convenio (y recibir sentencias en su contra) a ser sujeto activo del mismo y contribuir a su evolución.

El juez británico está obligado a actuar conforme al Convenio pero no está obligado a actuar conforme a la jurisprudencia del Tribunal Europeo de

38 Vid. nota 34.

39 En algunos ámbitos se ha admitido en mayor medida el efecto horizontal de la norma, como es el caso de la breach of confidence en los conflictos entre el derecho a la información y el derecho al honor, a la intimidad o a la propia imagen y en otros casi no se han producido cambios en este punto, como es por ejemplo el derecho de familia, en relación con los menores. Vid. PHILLIP, G.: "Clarity postponed: horizontal effect after Campbell" y "The common law, privacy and the Convention" y HARRIS-SHORT, S.: "Family Law and the Human Rights Act 1998" en ed. Helen Fenwick, Gavin Phillipson and Roger Masterman, Judicial Reasoning Under the Human Rights Act, Cambridge University Press, 2007. 
Derechos Humanos, está simplemente habilitado para tomar en consideración dicha jurisprudencia. El juez no está obligado a tomar la jurisprudencia del Tribunal como si de un mero precedente se tratase, y ello conlleva un importante cambio en el modo de razonar que hasta entonces se le suponía al juez británico, acostumbrado al sistema de precedentes. El juez podría desarrollar argumentos de principio — extraídos de la jurisprudencia del TEDH- y no seguir estrictamente reglas. En definitiva, el juez británico no está atado al nivel de protección de los derechos ofrecido por la jurisprudencia del Tribunal Europeo y podría ir más alláa ${ }^{40}$.

Pues bien, mientras que los jueces se han sentido legitimados para ser más creativos en un campo que siempre ha sido considerado de su dominio, el del derecho de creación judicial o common law, en otros ámbitos los jueces no se han sentido legitimados para separarse de las pautas de interpretación que se venían manejando hasta entonces. Curiosamente, la interpretación del artículo 2 de la Human Rights Act se ha seguido en su mayor parte como si de un supuesto de precedente se tratara. Veamos un caso concreto.

En materia de derecho a la intimidad, la Court of Appeal declaró que, a pesar de que el Tribunal Europeo de Derechos Humanos hubiera cambiado su interpretación de la información que debe ser calificada como íntima o privada a los efectos del artículo 8 del Convenio en el caso Von Hannover, que se decidió después de que la House of Lords hubiera resuelto el caso Campbell, sólo esta última podría adaptar su jurisprudencia sobre breach of confidence a este cambio de jurisprudencia en Estrasburgo. Por lo tanto, la Court of Appeal, siguió la jurisprudencia del caso Campbell, esperando a que la House of Lords tuviera a bien adaptarse al cambio de jurisprudencia del Tribunal de Europeo ${ }^{41}$. De esta forma, ese diálogo que algunos preconizaban que se podría mantener con Estrasburgo para influir en la dirección de la jurisprudencia europea sobre derechos sólo se producirá entre las máximas instancias judiciales del país y el Tribunal Europeo ${ }^{42}$.

Además, los tribunales británicos, de forma mayoritaria, han mantenido que no es posible innovar y extender el ámbito de aplicación de los derechos del Convenio en el Derecho interno británico más allá de lo que ha estable-

40 KLUG, F.: Values for a Godless Age. The Story of the UK's New Bill of Rights, Penguin Books, England, 2000, pág. 21.

41 En un conflicto parecido, la Court of Appeal siguió la jurisprudencia de la House of Lords, pero dio permiso a las partes para recurrir a esta última, de forma que los lores tuvieran la oportunidad de rectificar su jurisprudencia y adaptarla a la del Tribunal Europeo de Derechos Humanos. FELDMAN, D.: "Institutional Roles and Meanings of 'compatibility' under the Human Rights Act 1998, en FENWICK, H., PHILLIPSON, G., MASTERMAN, R.: Judicial Reasoning Under the Human Rights Act, Cambridge University Press, 2007, págs. 106 y 107.

42 Sobre ese posible diálogo y el papel de leader que podría jugar el Reino Unido en el desarrollo de la jurisprudencia del Tribunal Europeo de Derechos Humanos vid. MASTERMAN, R. "Aspiration or foundation. The status of the Strasbourg Jurisprudence and the 'Convention rights' in domestic law", cit., pág. 78. 
cido el propio Tribunal Europeo de Derechos Humanos en su jurispruden$\mathrm{cia}^{43}$.

EL "CONTROL DE INCOMPATIBILIDAD" Y LA "INTERPRETACIÓN CONFORME" al Convenio Europeo de Derechos Humanos

En cualquier caso, el verdadero hito histórico, el fin de la irreductible Britania, siguiendo con el símil del maravilloso cómic de Gostiny y Uderzo, se produce, sin duda alguna, con la introducción de un control análogo al control de constitucionalidad por la Human Rights Act. El parámetro de ese control no es otro que el Convenio Europeo de Derechos Humanos, si bien no en su totalidad, pues ya hemos visto como el artículo 1 reduce el ámbito de aplicación de la Human Rights Act respecto del ámbito de aplicación del Convenio.

Los jueces y tribunales británicos vienen obligados por el artículo 3 de la Human Rights Act a interpretar la legislación británica (Derecho primario y derivado: statutes y normas subordinadas) de forma compatible con el Convenio Europeo y cuando ello no sea posible, pueden declarar, por primera vez, la incompatibilidad de las leyes emanadas del Parlamento de Westminster con la Human Rights Act, y por lo tanto, con el Convenio Europeo de Derechos Humanos (art. 4 Human Rights Act).

Además, cada vez que un Ministro presenta un proyecto de Ley en el Parlamento de Westminster, debe hacer una declaración expresa sobre si, en su opinión, la norma es o no compatible con el Convenio (art. 19 Human Rights Act). Esto introduce necesariamente en el debate parlamentario argumentos de compatibilidad de la norma con los derechos del Convenio.

Como en el Reino Unido sigue en pie el principio de soberanía parlamentaria, la declaración de incompatibilidad no produce la invalidez de la ley [art. 3.2 b) Human Rights Act], aunque los tribunales pueden anular normas inferiores a la ley y actos de los poderes públicos, siempre que no deriven directamente de las leyes aprobadas por Westminster [art. 3.2 c) Human Rights $A c t]^{44}$. Tampoco produce la inaplicación de la ley, pues los jueces británicos deben aplicar la Ley, aunque sea contraria al Convenio Europeo de Derechos Humanos, sino que tal declaración de incompatibilidad lo que supone es una llamada de atención al Parlamento, una recomendación que, sin embargo, carece de fuerza vinculante, puesto que el Parlamento no está obligado a dero-

43 Vid. MASTERMAN, R.: "Aspiration or foundation. The status of the Strasbourg Jurisprudence and the 'Convention rights' in domestic law", cit.

44 El principio de soberanía sólo se aplica a las normas emanadas del Parlamento de Westminster, por lo que se ha introducido para las leyes escocesas un control de convencionalidad que conlleva la posibilidad de anular las leyes de dicho parlamento escocés [1998 Scotland Act]. El Parlamento de Westminster es el único soberano, la Devolution Act no ha cambiado esto [KLUG, F.: Values for a Godless Age. The Story of the UK's New Bill of Rights, cit., pág. 8]. 
gar o modificar la Ley que ha sido declarada incompatible ${ }^{45}$. $\mathrm{Y}$ en cualquier caso, la actuación del Parlamento no conlleva necesariamente la reparación de la vulneración concreta del derecho del particular ${ }^{46}$. Esto tiene relevancia en relación con la forma en que los jueces utilizan las cláusulas de los artículos 3 y 4 de la Human Rights $A c t^{47}$.

Pues bien, en ocasiones la utilización de la cláusula de interpretación conforme al Convenio del art. 3 de la Human Rights Act se ha hecho forzando el tenor literal de la Ley, buscando garantizar al particular de forma inmediata el remedio frente a la vulneración de su derecho, pues ello no se iba a conseguir mediante la declaración de incompatibilidad; mientras que en otras no se ha llevado a cabo dicha interpretación conforme, en una situación muy parecida, por considerar que existían numerosas implicaciones de política legislativa que lo desaconsejaban y que hacían necesario deferir la cuestión al Poder Legislativo. En estos casos se declara la incompatibilidad y se aplica, no obstante, la ley incompatible al caso concreto ${ }^{48}$.

45 BOGDANOR, V.: The New British Constitution, cit., pág. 60. De las 17 declaraciones de incompatibilidad que se produjeron desde la entrada en vigor de la Human Rights Act, en el año 2000, hasta enero de 2009, el Parlamento británico remedió 14 de las incompatibilidades, estaba analizando cómo remediar dos de las restantes y consultando públicamente qué hacer ante la única de las declaraciones que quedaba por remediar.

46 La no incorporación del artículo 13 del Convenio Europeo hace que no exista una obligación de reparar la vulneración del derecho convencional si no existía dicha obligación conforme al Derecho inglés. BOGDANOR, V.: The New British Constitution, cit., pág. 61.

47 Vid. GEARTY, C.: Principles of human rights adjudication, Oxford University Press, Oxford 2004, págs. 50 y ss sobre cómo afecta a la distribución de poderes el diferente uso que hagan los tribunales de ambas cláusulas.

48 Un ejemplo de ello lo tenemos en los casos de Ghaidan v. Mendoza [2004] 3 WLR 113 y Bellinger v. Bellinger [2003] UKHL 21; [2003] 2 AC 467 (HL). En el primero, la House of Lords consideró que era posible leer una sección de la Ley de Arrendamientos de 1977 [sección 2 (2) del Esquema 1 de la Rent Act] de forma que aunque literalmente sólo se permitía la subrogación del marido o de la mujer en el alquiler a la muerte del cónyuge siempre que hubiesen vivido conjuntamente "como marido y mujer", este derecho pudiera extenderse también a las parejas de hecho. En Bellinger en cambio, el mismo Tribunal consideró que era preferible hacer una declaración de incompatibilidad de la Ley por el juicio de política legislativa que suponía modificar la interpretación de la misma. La Ley [sección 11 (c) del Matrimonial Causes Act 1973], señalaba que desde el 31 de julio de 1971 el matrimonio sería nulo sólo si las partes contrayentes no eran respectivamente hombre y mujer. En Derecho inglés desde antiguo se había identificado el término hombre y mujer con el sexo de nacimiento. Esto afectaba evidentemente a los transexuales, que no podían casarse con alguien que tuviera su mismo sexo de nacimiento, a pesar de que ellos hubieran cambiado el suyo. Mrs Bellinger era una transexual que había nacido hombre y se había convertido legalmente en mujer. Mrs Belllinger quería que los tribunales ingleses declarasen que su matrimonio, que ya duraba 20 años, era válido y subsistía. Mrs Bellinger no vio reparada la vulneración de su derecho al matrimonio por los tribunales ingleses (art. 12 del Convenio en relación con el artículo 8 del mismo), ya que éstos aplicaron la Ley una vez declarada la incompatibilidad con el Convenio y deferida la solución de la cuestión al Legislativo.

Vid. KAVANAGH, A.: "Choosing between sections 3 and 4 of the Human Rights Act 1998: judicial reasoning after 'Gaidhan v. Mendoza', en Helen Fenwick, Gavin Phillipson and Roger Masterman, Judicial Reasoning Under the Human Rights Act, Cambridge University Press, 2007, págs. 117-128; FELDMAN, D.: “Institutional Roles and Meanings of 'compatibility' under the Hu- 
Ante la declaración de incompatibilidad el Parlamento puede o no reaccionar: hasta ahora lo ha venido haciendo ${ }^{49}$. La Human Rights Act contempla también una reacción rápida, más allá de la modificación o derogación de la Ley por los cauces del procedimiento legislativo ordinario. El artículo 10 (2) permite a los Ministros modificar la legislación declarada incompatible cuando consideran que hay razones de peso que compelen en tal dirección, si bien la modificación (hecha a través de una remedial order) debe ser aprobada por las dos Cámaras del Parlamento mediante una resolución, transcurridos 60 días desde que se les presentara el borrador por el Ministro [Schedule 2, 2 (a) $]^{50}$. Si el Ministro considera que la urgencia le impide presentar ese borrador y esperar a que el Parlamento se pronuncie, debe señalarlo en la orden y no tiene que esperar a la resolución de las Cámaras [Schedule 2, 2 (b) y 4]. Ahora bien, de forma también inmediata el Ministro deberá entregar la orden al Parlamento y si este no se pronuncia en los 120 días desde que se aprobó la orden, entonces la orden dejará de surtir efectos, pero sólo hacia el futuro [Schedule 2, 4 (4)].

En fin, aunque el principio de soberanía parlamentaria no se haya visto afectado en su esencia, indudablemente se ha visto debilitado por la entrada en vigor de la Human Rights Act. Por primera vez una norma sirve de parámetro de interpretación de todo el Derecho anterior. Además, por primera vez una Ley vincula al Parlamento en cuanto que las leyes futuras deberán ser interpretadas conforme al Convenio Europeo de Derechos Humanos y podrán ser declaradas incompatibles en virtud de la Human Rights Act ${ }^{5}$. El parecido con una Constitución es próximo en este punto, aunque no llegue a identificarse por completo, al menos en el sentido de una Constitución rígida, pues, ciertamente, el Parlamento de Westminster conserva la competencia para derogar esta norma en el futuro (aunque debe hacerlo explícitamente) ${ }^{52}$.

Estamos en presencia, pues, no de un factor de supralegalidad, basado en una especial rigidez procedimental, sino de un factor de resistencia normativa (fuerza pasiva) basado en una reserva de estricta denominación (expresa y por eso formal). Se ha atenuado, quizás, la flexibilidad de esta parte de la Constitución británica, pero esa flexibilidad no se ha mudado en auténtica rigidez, esto es, la Constitución británica sigue siendo jurídicamente, después de la en-

man Rights Act 1998, en Helen Fenwick, Gavin Phillipson and Roger Masterman, Judicial Reasoning Under the Human Rights Act, Cambridge University Press, 2007, pág. 108. Sonia HarrisShort habla de deferencia al Parlamento en una cuestión de políticas públicas sensible [HARRISSHORT, S.: "Family Law and the Human Rights Act 1998: judicial restraint or revolution?", en Helen Fenwick, Gavin Phillipson and Roger Masterman, Judicial Reasoning Under the Human Rights Act, Cambridge University Press, 2007, pág. 313]

49 BOGDANOR, V.: The New British Constitution, cit., pág. 60.

50 Sobre la introducción de esta cláusula, GEARTY, C.: Principles of human rights adjudication, Oxford University Press, Oxford 2004, pág. 49.

51 BOGDANOR, V.: The New British Constitution, cit., pág. 59.

52 Idem, págs. 59 y 60 y BRADLEY, A.W.: "The sovereignty of Parliament- in Perpetuity?", en The Changing Constitution, cit., pág. 48. 
trada en vigor de la Human Rights Act, una Constitución flexible. Sin embargo, muchas veces no ata tanto lo que se puede y no se puede hacer jurídicamente hablando, sino lo que la realidad permite, y es dudoso que tras unos años de funcionamiento, cualquier Gobierno británico, por contrario que sea a la norma, pueda volver hacia atrás como si la Human Rights Act y el control de la actividad de los poderes públicos británicos nunca hubiera existido.

\section{CONCLUSIÓN}

El Reino Unido, siempre tan fóbico frente a lo importado del viejo Continente, ha dado cabida al Derecho constitucional internacional europeo, a través de la incorporación del Convenio Europeo de Derechos Humanos como Derecho interno, y se ha rendido a razonamientos como el de la proporcionalidad ante la injerencia en los derechos de los individuos, o el de la legitimidad de los objetivos perseguidos por el Estado para limitar los derechos no absolutos. Por otro lado, la Human Rights Act, sobre todo por el juego de sus artículos 3 y 4, ha abierto una espita, si no lo había hecho ya la incorporación del Reino Unido a la UE, por la que se cuela inevitablemente el Derecho constitucional europeo (con sus técnicas de argumentación específicas, como la de la argumentación conforme, y el análisis de la constitucionalidad de las disposiciones normativas con fuerza de ley).

El impacto de esta norma, no ya sólo en el Reino Unido, sino en el devenir del ordenamiento jurídico internacional europeo, es y será enorme. Europa, y en este caso, el Reino Unido, han dado un nuevo paso en el acercamiento de su Derecho Público, que comenzó siendo un simple acercamiento a nivel internacional y que luego ha ido calando de forma más o menos perceptible por los intersticios del Derecho interno de los diferentes países del Continente. Sin duda, después de lo visto, se comprenderá por qué desde el propio Reino Unido se califica a esta Human Rights Act como el mayor hito en la historia constitucional del Reino Unido en los últimos 100 años.

\section{TitLE: The Human Rights Act, a written Bill of Rights as the Continental ones?}

ABSTRACT: This article explores the way in which the Human Rights Act was introduced in the political debate by the Labour Party and how it was passed without much noise despite the foreseeable impact that it might have in the British legal system. More than ten years are gone since then, so it seems the right time to analyze its effects. For the first time, the British judges can carry out a conventional control of the Acts of Parliament and make a declaration of incompatibility of these Acts with the European Convention on Human Rights. This declaration of incompatibility does not affect the validity of the law, but it has clearly modified the way in which the British judges approach the interpretation of the law. British judges are now adopting constitutional techniques long used in the continental Europe. After the analysis of the Human Rights Act we conclude that the British legal system is coming closer to the constitutional systems that have dominated Europe in the last century. 
RESUMEN: Este artículo explora cómo se aprobó la Human Rights Act, a inicitativa del Partido Laborista y sin que el asunto levantara mucha polvareda, a pesar del impacto que la aprobación de dicha Ley tendría, sin duda, en el sistema legal británico. Han pasado más de diez años desde que la Human Rights Act fuera aprobada por el Parlamento inglés y no es mala fecha para realizar una valoración de los efectos que ha tenido la norma en el mencionado sistema. Por primera vez, los jueces británicos pueden llevar a cabo un control de convencionalidad de las leyes aprobadas por el Parlamento y hacer una declaración de incompatibilidad de dichas leyes con el Convenio Europeo de Derechos Humanos. La declaración de incompatibilidad no afecta a la validez de la ley pero sí influye en la forma en la que los jueces británicos se aproximan a la interpretación de las leyes. Los mencionados jueces están recurriendo en mayor medida a técnicas de interpretación constitucional utilizadas desde hace tiempo en el viejo continente. La Human Rights Act ha producido un acercamiento evidente entre el sistema británico de Constitución flexible y el europeo de Constitución rígida.

KeY wORDS: British Law. Fundamental Rights. European Convention on Human Rights. Judicial Review. Constitutional Interpretation. Comon Law. Civil Law.

Palabras clave: Derecho británico. Constitución flexible y constitución rígida. Derechos fundamentales. Convenio Europeo de Derechos Humanos. Tutela Judicial. Interpretación constitucional. 